\title{
TIA-1 expression in hairy cell leukemia
}

\author{
Naoyoshi Mori ${ }^{1}$, Yoshiko Idate Murakami ${ }^{1}$, Satoko Shimada ${ }^{1}$, Sachiko Iwamizu-Watanabe ${ }^{1}$, \\ Yoriko Yamashita $^{1}$, Yuichi Hasegawa ${ }^{2}$, Hiroshi Kojima ${ }^{2}$ and Toshiro Nagasawa ${ }^{2}$ \\ ${ }^{1}$ Department of Pathology of Biological Response, Nagoya University Graduate School of Medicine, \\ Showa-ku, Nagoya, Japan and ${ }^{2}$ Division of Hematology, Institute of Clinical Medicine, University of Tsukuba, \\ Tsukuba, Japan
}

\begin{abstract}
We measured T-cell intracellular antigen-1 (TIA-1) expression in neoplastic cells from patients with hairy cell leukemia. Five of nine cases were positive for cytoplasmic TIA-1, with a small, dot-like, granular expression pattern. However, neoplastic cells were granzyme B- and perforin- negative in all cases. Other positive markers were CD20 in 9/9 cases, CD19 in 9/9 cases, DBA44 in 8/9 cases, LeuM5(CD11C) in 8/9 cases, IL-2R(CD25) in 7/9 cases, CD103 in 7/9 cases, FMC7 in 6/9 cases, and tartrate- resistant acid phosphatase in 5/7 cases. We also analyzed TIA-1 expression in 94 B cell lymphomas, including 19 diffuse, large cell lymphomas, 19 mantle cell lymphomas, six follicular lymphomas, two extranodal marginal zone B-cell lymphomas, 13 nodal marginal zone B-cell lymphomas, one mediastinal large-cell lymphoma, 19 diffuse small-cell lymphomas, 14 myelomas, and one splenic lymphoma with villous lymphocytes. All cases were negative for TIA-1 expression. Based on these findings, TIA-1 expression in neoplastic cells of low-grade B-cell lymphomas may be a good diagnostic marker for hairy cell leukemia. Moreover, TIA-1 reactivity in lymphomas does not necessarily indicate a T- or NK-cell derivation.
\end{abstract}

Modern Pathology (2004) 17, 840-846, advance online publication, 9 April 2004; doi:10.1038/modpathol.3800129

Keywords: hairy cell leukemia; TIA-1; cytotoxic protein

The predominant cytotoxic molecules are perforin, granzyme, and T-cell intracellular antigen-1 (TIA1). ${ }^{1-3}$ Expression of these proteins has been reported in cytotoxic $\mathrm{T}$ cells ${ }^{4-6}$ and natural killer cells (NK cells). ${ }^{6,7}$ These proteins are also expressed in T-cell or NK-cell neoplasms, ${ }^{8-11}$ including large granular lymphocyte leukemia, NK-cell leukemia/lymphoma, ${ }^{12-14}$ hepatosplenic T-cell lymphoma, ${ }^{15-17}$ subcutaneous panniculitic T-cell lymphoma, ${ }^{18,19}$ enteropathy-type T-cell lymphoma, ${ }^{20}$ and anaplastic large-cell lymphoma. ${ }^{21}$ Perforin functions by making a hole in the target cell membrane. Then, TIA-1 and granzymes enter the cytoplasm through the pore made by perforin and activate apoptosis-related proteins. $^{9,10,21}$ Perforin and granzymes are only expressed in cytotoxic cells upon activation and are associated with induction of apoptotic activity. TIA-1, however, is expressed in cytotoxic T cells, regardless of their activation status, and in myeloid cells. ${ }^{6-8}$

Cytotoxic molecules are also expressed in some cases of Hodgkin's lymphoma. ${ }^{21}$ However, no

Correspondence: N Mori, Nagoya University Graduate School of Medicine, Tsurumai-cho 65, Showa-ku, Nagoya 466-8550, Japan. E-mail: naoyoshi@med.nagoya-u.ac.jp

Received 23 October 2003; revised and accepted 9 February 2004; published online 9 April 2004 reports have detected cytotoxic molecule expression in B-cell lymphomas. We incidentally detected TIA1 expression in some cases of hairy cell leukemia. The aim of our study, therefore, is to analyze TIA-1 expression in hairy cell leukemia and to determine whether other B cell lymphomas express TIA-1.

\section{Materials and methods}

Fresh-frozen tissues were available from nine cases of hairy cell leukemia. Of these, four splenic tissues, three bone marrow clot sections, and two peripheral blood samples were obtained. Paraffin tissue sections were also available in six cases. Three bone marrow biopsy specimens, one bone marrow clot section, and four splenic tissues were available in paraffin tissue specimens. TIA-1 expression was also studied in paraffin tissue sections from 94 cases of various B-cell lymphomas.

\section{Peripheral Blood Analysis}

Flow cytometric analysis was performed in four cases. Peripheral blood was taken in heparincontaining tubes, and mononuclear fractions were collected by gradient centrifugation method using Ficoll-Paque (Pharmacia, Uppsala, Sweden). Cells 
were washed twice with phosphate-buffered saline (PBS), and incubated with each antibodies according to the instructions of the manufacturers. After 30 min incubation on ice, cells were washed twice with PBS containing albumin and azide. FACScan and software (Consort 30 or Cell Quest) were used for analysis (Becton Dickinson, San Jose, CA, USA). All antibodies for flow cytometry were purchased from Becton Dickinson. Fluorescent labeled antibodies were for CD5, 10, 19, 20, 21, 22, 23, 24, 25, 38, 11a, 11c, and FMC7 and these clones were L17F12, H10a, HIB19, 2H7, B-ly4, S-HCL-1, M-L233, ML-5, M-A251, HIT-2, G43-25B, B-ly6, and FMC7, respectively. These antibodies were labeled with fluorescein isothiocyanate (FITC), or phycoerythrin (PE). Negative control cells were stained with each isotype antibodies labeled with adequate fluorescent dyes (mouse IgG1, or IgG2 labeled with FITC, or PE). Hairy cells were targeted on front scatter and side scatter plotgraph if hairy cells were lower than $95 \%$ of mononuclear cells.

\section{Frozen Tissue Analysis}

Fresh frozen tissues were fixed with periodate-lysinparaformaldehyde, ${ }^{22}$ frozen, cut with a cryostat to a thickness of $6-8 \mu \mathrm{m}$, fixed with acetone for $10 \mathrm{~min}$, reacted with primary antibodies, and stained with an avidin-biotin-peroxidase complex method. ${ }^{23}$ Primary antibodies used were CD5(Leu1) and CD11c(LeuM5) (Becton Dickinson, San Jose, CA, USA), CD25(IL-2R) (Becton Dickinson, Mountain View, CA, USA), FMC7 (Sera-Lab, Sussex, UK), CD103 (Immunotech, Marseille, France), DBA44 (DAKO, Copenhagen, Denmark), CD20(B1) and CD19(B4), (Coulter, Hialeah, FA), TIA-1 and perforin (T Cell Diagnostics, Cambridge, MA, USA), and granzyme B (Monosan, Ueden, Netherlands).

For immunoelectron microscopy, after performing the immunoperoxidase protocol, specimens were fixed with $1.25 \%$ glutaraldehyde for $15 \mathrm{~min}$ and washed three times with cold phosphate-buffered saline. Specimens were then reacted with diaminobenzidine solution containing $0.01 \%$ hydrogen peroxide for $5 \mathrm{~min}$ at room temperature. They were postfixed with osmium tetroxide, dehydrated, embedded, and observed under an electron microscope without counterstain. Details of immunoelectron microscopy have been described elsewhere. ${ }^{23}$

\section{Paraffin Tissue Analysis}

For paraffin sections, tissues were fixed with $10 \%$ formaldehyde and embedded in paraffin. Sections 2-4 $\mu \mathrm{m}$ thick were prepared and stained with hematoxylin and eosin (H\&E). The avidin-biotinperoxidase complex method ${ }^{24}$ was used for antibody staining. Antibodies used were CD20 (L26) and CD79a (mb-1) (DAKO, Copenhagen, Denmark), TIA-1 and perforin ( $\mathrm{T}$ Cell Diagnostics, Cambridge, MA, USA), granzyme B (Monozan, Uden, Netherlands), CD43(MT1) (Immunochemicals, Biochemicals and Diagnostics, Emmerbruecke, Switzerland), and CD45RO (UCHL-1) (Nichirei Corp., Tokyo, Japan).

\section{Results}

In all, nine cases of hairy cell leukemia were studied. The average age of the patients was 65 years, and of these, six were males and three were female patients. All cases had some degree of splenomegaly and some had marked splenomegaly (Table 1). One patient had liver involvement. In the four cases where bone marrow specimens were available, the bone marrow was diffusely infiltrated with tumor cells in all cases.

Wright staining of a bone marrow smear revealed atypical lymphoid cells with abundant and pale cytoplasms (Figure 1a). Hairy projections were identified in almost all cases investigated with electron or phase contrast microscopy (Table 1). Most patients had leukopenia, although two cases had leukocytosis, suggesting them to be the Japanese type variant.

Flow cytometric analysis was performed in four cases (Case No. 3, 4, 5 and 8). As a result, CD19, 20, and CD11c were all positive (4/4). CD25 was positive in $3 / 4$ cases, FMC7 in $2 / 2$, CD21 in $2 / 3$, CD22 in $2 / 2$, CD23 in $1 / 3$, CD24 in $0 / 2$, CD38 in 0/3, CD11a in 1/2, CD5 in 0/4, and CD10 in 0/4,

Table 1 Clinical features of the cases

\begin{tabular}{|c|c|c|c|c|c|c|}
\hline Case & Age (years) & Sex & Hematological findings & Splenomegaly & Therapy & Prognosis \\
\hline 1 & 76 & $\mathrm{M}$ & Non-remarkable & + & Splenectomy & CR (1) \\
\hline 2 & 72 & $\mathrm{~F}$ & Pancytopenia, hairy projections (PC) & + & Splenectomy & CR (11) \\
\hline 3 & 44 & M & Pancytopenia, hairy projections (PC) & + & Splenectomy & PR (5) \\
\hline 4 & 56 & M & Leukocytopenia (2900), hairy projections (PC) & + & Splenectomy & Unknown \\
\hline 5 & 69 & M & Leukocytosis (24600), hairy projections (PC) & + & IFN & PR (20) \\
\hline 6 & 72 & $\mathrm{~F}$ & Leukopenia & + & Unknown & Unknown \\
\hline 7 & 53 & $\mathrm{M}$ & Leukocytosis (9200) & + & Splenectomy & Unknown \\
\hline 8 & 65 & M & Pancytopenia, hairy projections (EM) & + & IFN & CR (13) \\
\hline 9 & 79 & $\mathrm{~F}$ & Leukopenia, hairy cells & + & Unknown & Unknown \\
\hline
\end{tabular}

PC, phase contrast microscopy; EM, electron microscopy; CR (11), complete remission (11 years); PR, partial remission; IFN, interferon. 
842
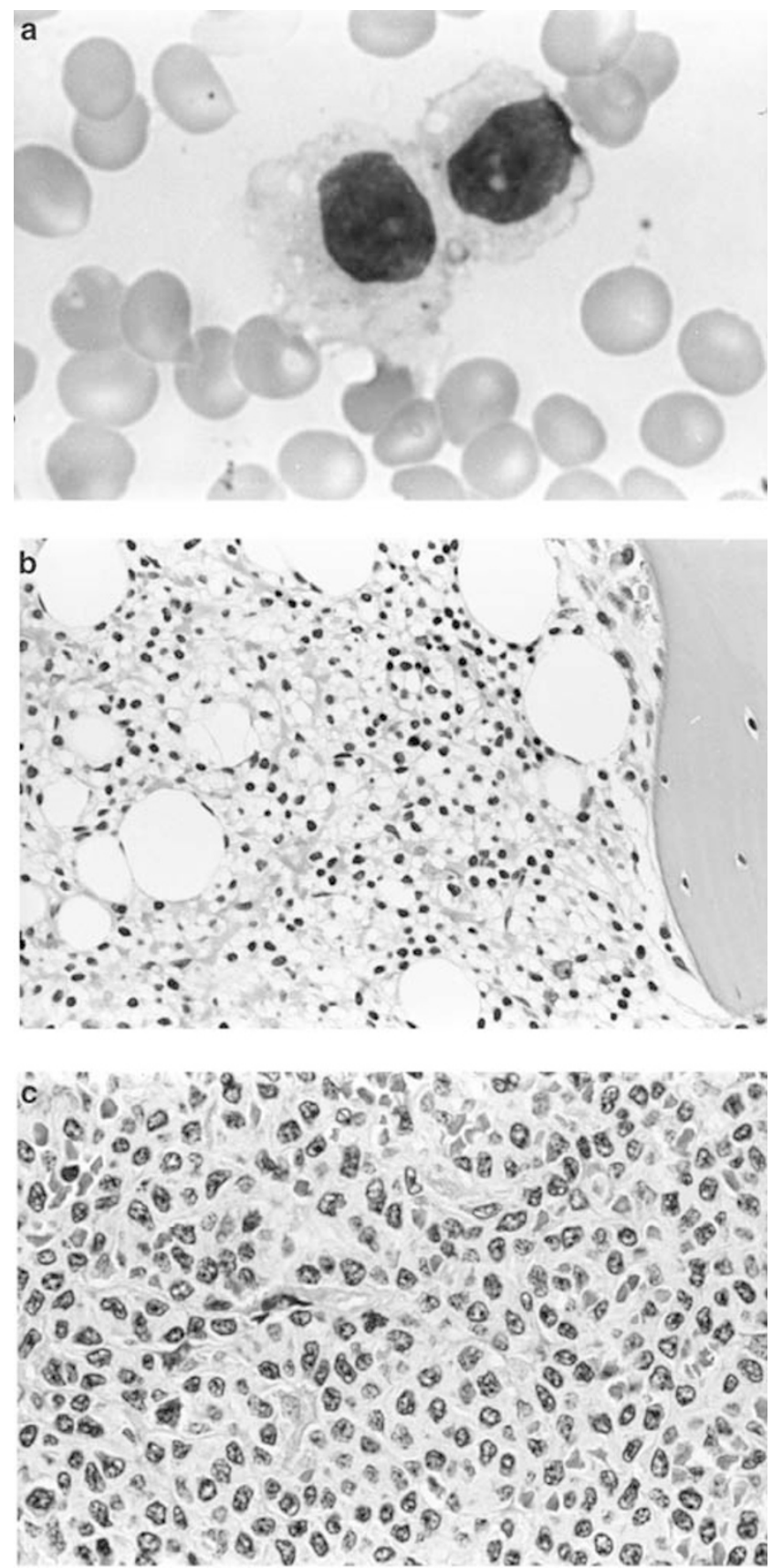

Figure 1 (a) Wright staining of a bone marrow smear reveals atypical lymphoid cells with abundant and pale cytoplasms (case 3) and (b), (c) H\&E section of hairy cell leukemia; (b) Bone marrow $(\times 340)$, (c)spleen $(\times 680)$. The neoplastic cells have an ample, pale cytoplasm and a medium-sized, round, sometimes slightly irregular nucleus.

respectively. Positivity was defined when more than $60 \%$ of hairy cells were positively stained.

In paraffin tissue sections, neoplastic cells were small to medium-sized with round nuclei and ample, pale cytoplasm in the bone marrow and spleen specimens (Figure $1 \mathrm{~b}$ and $\mathrm{c}$ ). Blood lakes were occasionally observed in spleens. Five of seven cases investigated were tartrate-resistant acid phosphatase (TRAP)-positive. Of these, frozen tissue specimens were available in all cases, and paraffin tissues were available in six cases. In all, 3/6 paraffin tissue sections and 5/9 frozen tissue specimens were TIA-1 positive (Figure 2a and b). Granzyme B and perforin were not positive in any cases. Pan B cell markers, such as CD19 (B4) and CD20 (B1), were positive in all cases (Figure 3). Other positive markers were DBA44 in 8/9, LeuM5(CD11c) in 8/9, IL-2R(CD25) in 8/9, CD103 in 7/9, FMC7 in 6/9 (Figures 4-6), and TRAP in 5/7 cases. CD5 was not expressed in any cases (Table 2). Immunoelectron microscopy revealed TIA-1 expression in the perigranular region of neoplastic cells (Figure 7). The positive reactivity was not localized in the ribosome lamellar complexes we examined so far.

\section{Discussion}

Hairy cell leukemia, formerly known as leukemic reticuloendotheliosis, ${ }^{25-31}$ is characterized by bone marrow $^{32}$ and splenic involvement by small to medium-sized neoplastic cells with abundant cytoplasm and hairy projections. ${ }^{3-35}$ In our present study, hairy cytoplasmic projections were observed in the peripheral blood in most cases $(7 / 9)$ by electron or phase-contrast microscopy. ${ }^{34,35}$ Furthermore, TRAP was positive in most cases (5/7 cases studied). ${ }^{26,31,34,35}$ In the bone marrows and spleens studied, neoplastic cells had a small to mediumsized, round nucleus and ample, pale cytoplasm. All patients had splenomegaly, and in some cases, blood lakes were observed by light microscopy. ${ }^{36}$ Therefore, we considered these cases to fit the category of hairy cell leukemia. Patients with hairy cell leukemia usually have low peripheral blood leukocyte counts. ${ }^{34,35}$ However, the leukocyte count in case 5 was 24600 and may represent the Japanese variant, ${ }^{37-39}$ as opposed to the Western type hairy cell variant. ${ }^{40}$ In this case of hairy cell leukemia, the neoplastic cells were CD5-, CD11c + , and CD25-, a phenotype consistent with a Japanese variant. ${ }^{37-39} \mathrm{In}$ hairy cell leukemia, in addition to pan-B-cell markers such as CD19(B4), CD20(B1 or L26), and CD79a, various markers have been reportedly positive, including DBA44, CD11c(LeuM5), CD25(IL2R), CD103, and FMC7. ${ }^{34,35,41-44}$ In this study, these markers were largely positive, with DBA44 positivity in $8 / 9$ cases, CD11c in $8 / 9$ cases, CD25 in 7/9 cases, CD103 in 7/9 cases, and FMC in 6/9 cases, respectively. None of the cases were positive for CD5. Cytotoxic proteins including perforin, granzyme B, and TIA-1 are expressed in various cytotoxic T-cell and NK cell lymphomas. ${ }^{10,11,13,14}$ These lymphomas generally express all of these proteins. Nasal lymphoma shows strong perforin, ${ }^{12}$ granzyme B, and TIA-1 expression. Cytotoxic proteins are also reportedly expressed in certain cases of Hodgkin's lymphoma. ${ }^{21}$ It has been reported that neoplastic cells from patients with hepatosplenic T-cell lymphoma only express TIA- $1 .{ }^{15}$ 
Table 2 Histochemical and immunohistochemical findings of hairy call leukemia

\begin{tabular}{|c|c|c|c|c|c|c|c|c|c|c|c|c|}
\hline Case & TIA-1 & $\operatorname{grz} B$ & $p f$. & CD20 & CD19 & $D B A 44$ & LeuM5 & $I L-2 R$ & CD103 & FMC7 & CD5 & TRAP \\
\hline 1 & + & - & - & + & + & + & + & $+1-$ & + & + & - & ND \\
\hline 2 & + & - & - & + & + & + & + & + & + & + & - & + \\
\hline 3 & + & - & - & + & + & + & + & + & + & + & - & + \\
\hline 4 & + & - & - & + & + & - & + & + & - & - & - & + \\
\hline 5 & + & - & - & + & + & + & + & - & + & + & - & + \\
\hline 6 & - & - & - & + & + & + & - & + & - & - & - & - \\
\hline 7 & - & - & - & + & + & + & + & - & + & + & - & - \\
\hline 8 & - & - & - & + & + & + & + & + & + & + & - & + \\
\hline 9 & - & - & - & + & + & + & + & + & + & - & - & ND \\
\hline
\end{tabular}

GrzB, granzyme B; pf, perforin; TRAP, tartrate-resistant acid phoshatase; ND, not done.
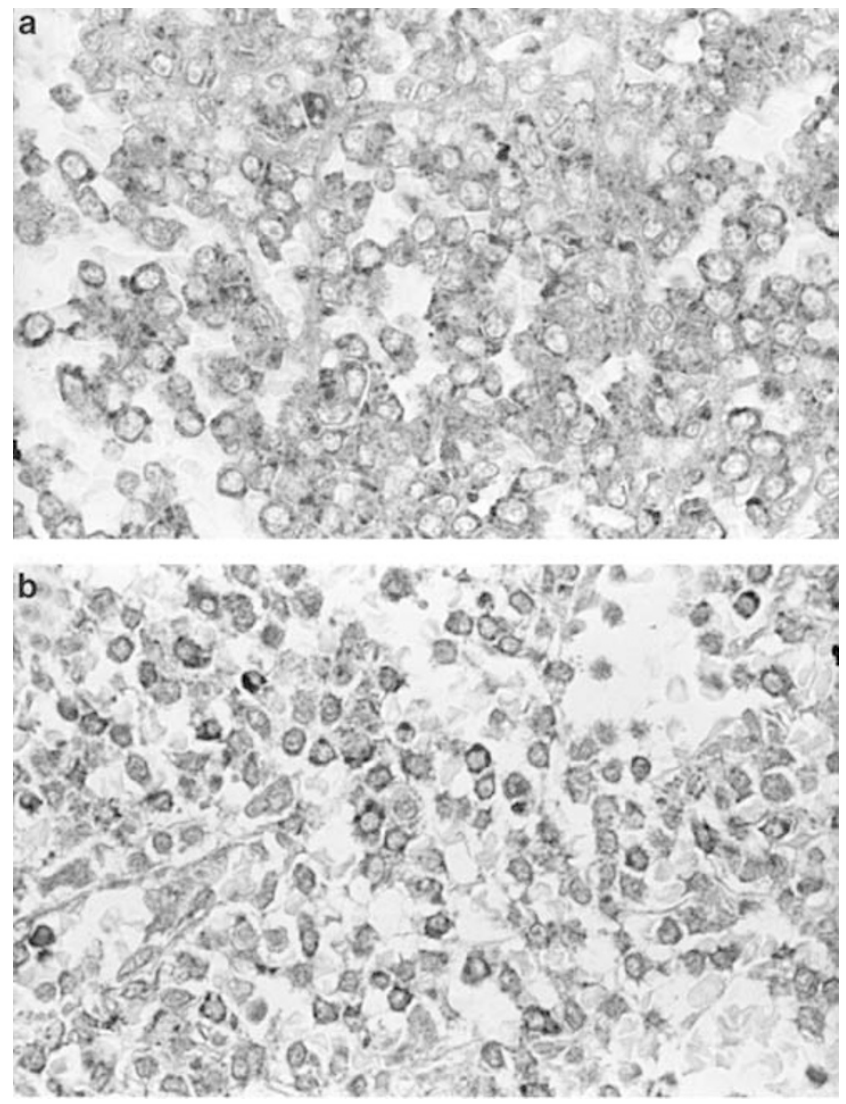

Figure 2 TIA-1 immunostaining reveals positive granular reactivity in the cytoplasm of most neoplastic cells. (a) case 1, (b) case $2(\times 340)$.

Cooke et $a l^{15}$ reported that hepatosplenic T-cell lymphoma is a distinct and rare entity, with distinct clinicopathologic features characterized by its extranodal hepatosplenic presentation and sinusal/ sinusoidal tropism of the neoplastic $\mathrm{T}$ cells. These tumors reportedly expressed TIA-1, although only one of eight cases expressed perforin. ${ }^{15}$ They therefore considered that hepatosplenic T-cell lymphoma cells may be functionally immature and not yet capable of cytotoxic function. ${ }^{15}$ Although TIA-1 expression, in the absence of granzyme and perforin expression, is similar between the cases of hairy cell leukemia and hepatosplenic T-cell lymphoma, ${ }^{15,16}$

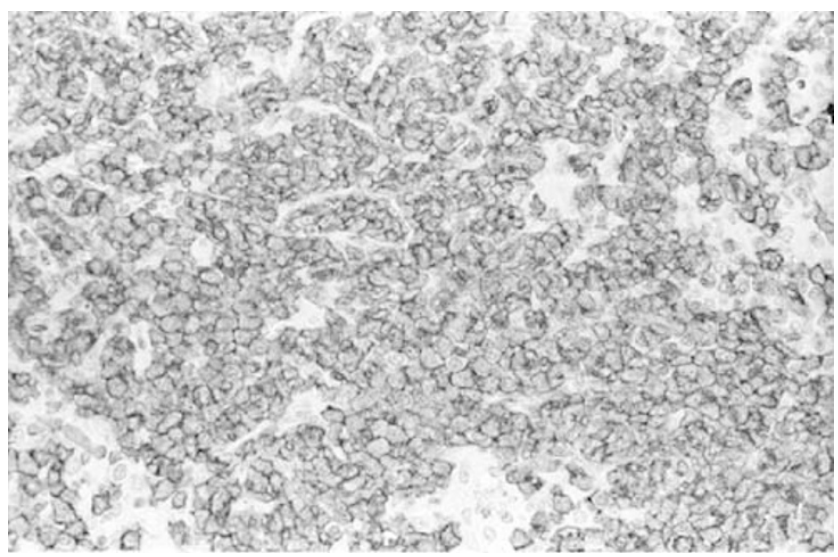

Figure 3 CD20 immunostaining reveals positive reactivity in the cytoplasm of neoplastic cells $(\times 340)$.

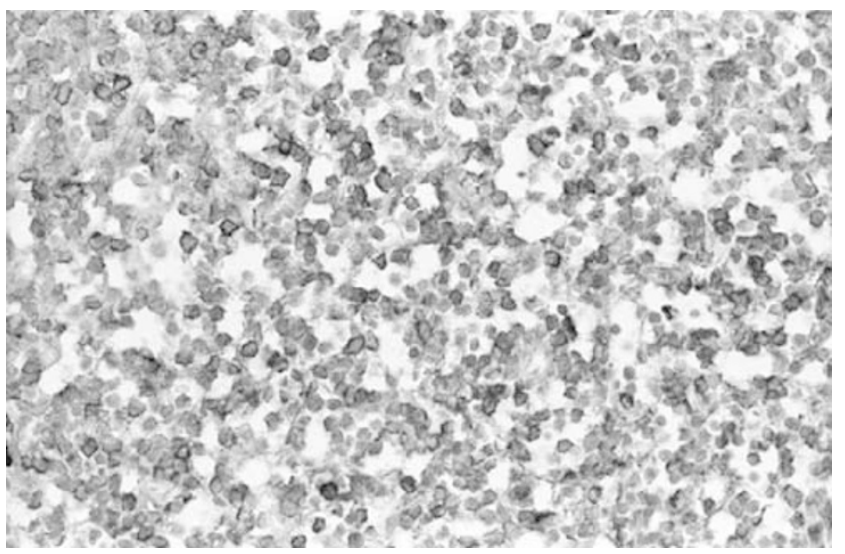

Figure 4 DBA44 immunostaining reveals positive reactivity in the neoplastic cells $(\times 340)$.

the mechanism underlying their expression might be different. Since hairy cell leukemia is a B-cell lymphoma, it is not expected to have a role in cytotoxic function.

Recent studies indicated that cytotoxic $\mathrm{T}$ cells possess azurophilic cytoplasmic granules containing perforin, granzyme $\mathrm{A}$ and $\mathrm{B}$, and TIA- 1 . $^{3}$ Perforin has a role in forming pores in target cell membranes. Then, granzymes and TIA-1 trigger a 


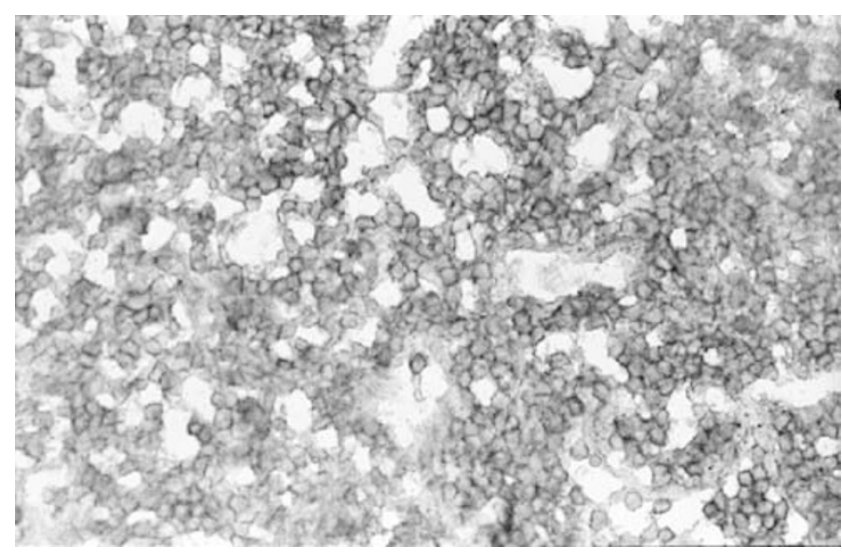

Figure 5 IL2-R (CD25) immunostaining reveals positive reactivity in the neoplastic cells $(\times 340)$.

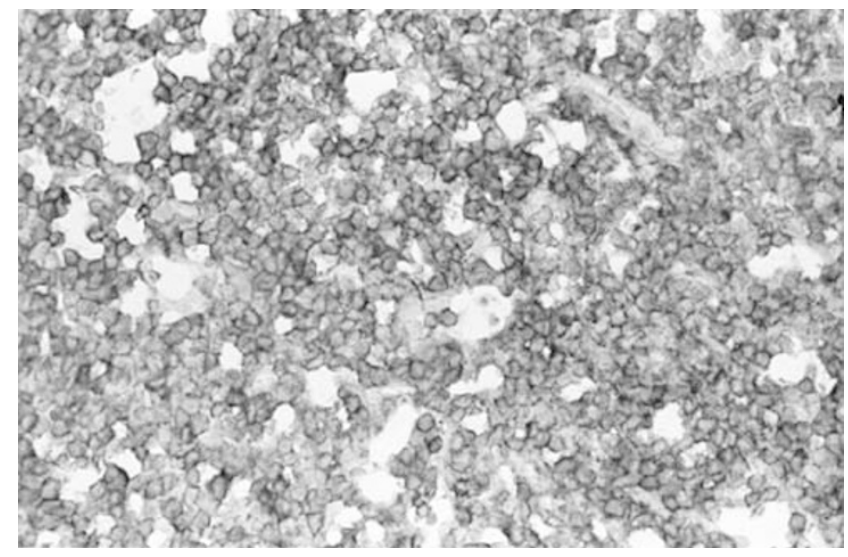

Figure 6 LeuM5 (CD11c) immunostaining reveals positive reactivity in the neoplastic cells $(\times 340)$

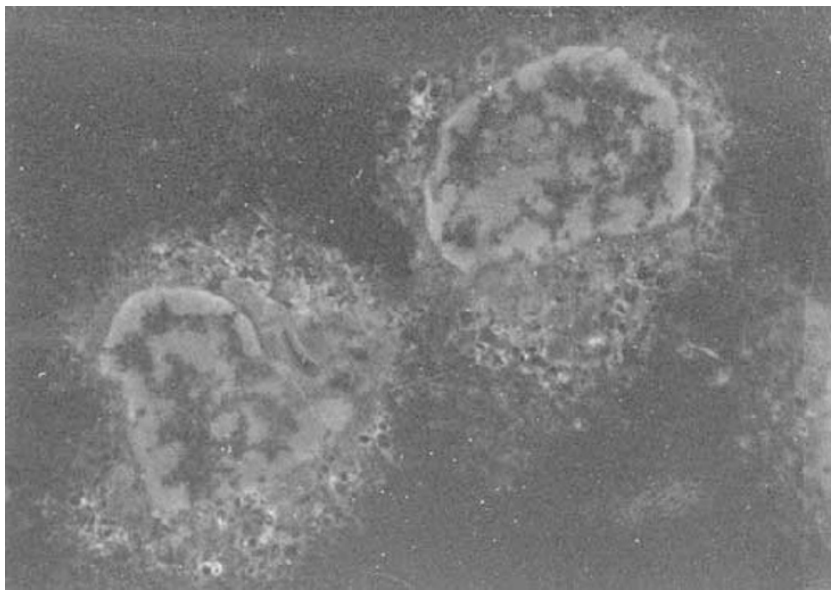

Figure 7 Immunoelectron microscopy reveals positive reactivity in the perigranular spaces of the neoplastic cells $(\times 5000)$.

process leading to apoptotic DNA fragmentation of target cells. ${ }^{8,9,21}$ Medley et $a l^{6}$ localized TIA-1 to the membrane of cytotoxic granules in NK cells by immunoelectron microscopy. They, therefore, renamed this protein granule membrane protein of $17 \mathrm{kDa}$, GMP-17, given its subcellular localization. ${ }^{6}$
Our immunoelectron microscopy results support their finding of TIA-1 reactivity in the perigranular spaces of neoplastic cells.

Azurophilic granules have also been observed in neoplastic hairy cell leukemia. ${ }^{28,29}$ We, therefore, speculate that TIA-1 expression may account for the presence of azurophilic granules in hairy cells. TIA1 is also expressed in granulocytes, ${ }^{6,7}$ in addition to cytotoxic T cells and NK cells. Therefore, TIA-1 expression is not necessarily related to the induction of apoptosis-related proteins.

Beck et $a l^{2}$ reported that murine TIA-1 is predominantly expressed in brain, testis, and spleen. TIA-1 has been suggested to be incorporated in hairy cells, rather than being endogenously expressed, because hairy cells have a role in phagocytosis ${ }^{30}$ as well as a receptor for cytophilic antibodies. ${ }^{27}$ However, this mechanism is unlikely because most neoplastic cells contain TIA-1 granules in their cytoplasm, suggesting endogenous TIA-1 production rather than exogenous intake.

Although the nature of the neoplastic cells of hairy cell leukemia still remains to be clarified, the neoplastic cells do not seem to be restricted to a defined lineage. ${ }^{45}$ In addition, various cytokines such as fibroblast growth factor ${ }^{45,46}$ or TNFalpha, ${ }^{47,48}$ are reportedly produced in hairy cells, showing their unique nature. TIA-1 finding in the neoplastic cells of hairy cell leukemia may be helpful for elucidating its nature.

Although the mechanism of TIA-1 expression in hairy cell leukemia neoplastic cells is unknown, TIA-1 is a good marker for diagnosing hairy cell leukemia among low-grade B-cell lymphomas.

\section{Acknowledgements}

We thank Mr N Misawa, Ms K Kato and C Fujinaka of the Department of Pathology of Biological Response, Nagoya University Graduate School of Medicine, Mr K Sako of Kamo hospital, Toyota City, and Ms S Sato of Tsukuba University, Tsukuba city, for their excellent technical assistance. This work was supported in part by the Grant-in-Aid for Scientific Research from the Ministry of Education, Culture, Sports, Science and Technology (No. 15590300).

\section{References}

1 Griffiths GM, Mueller C. Expression of perforin and granzymes in vivo: potential diagnostic markers for activated cytotoxic cells. Immunol Today 1991;12: 415-419.

2 Beck ARP, Medley QG, O’Brien S, et al. Structure, tissue distribution and genomic organization of the murine RRM-type RNA binding proteins TIA-1 and TIAR. Nucleic Acids Res 1993;21:3699-3704.

3 Kawakami A, Tian Q, Duan X, et al. Identification and functional characterization of a TIA-1-related protein. Proc Natl Acad Sci USA 1992;89:8681-8685. 
4 Tian Q, Streuli M, Saito $\mathrm{H}$, et al. A polyadenylate binding protein localized to the granules of cytolytic lymphocytes induces DNA fragmentation in target cells. Cell 1991;67:629-639.

5 Takeuchi Y, Nishimura T, Gao XH, et al. Perforin is expressed in CTL populations generated in vivo. Immunol Lett 1992;31:183-187.

6 Medley QG, Kedersha N, O’Brien S, et al. Characterization of GMP-17, a granule membrane protein that moves to the plasma membrane of natural killer cells following target cell recognition. Proc Natl Acad Sci USA 1996;93:685-689.

7 Shimane M, Tani K, Hibino $\mathrm{H}$, et al. Significant expression of G-CSF-induced gene-1(GIG-1)protein in myeloid cells and NK cells. J Leukoc Biol 1999;65: 109-116.

8 Boulland M-L, Kanavaros P, Wechsler J, et al. Cytotoxic protein expression in natural killer cell lymphomas and in $\alpha \beta$ and $\gamma \delta$ peripheral T-cell lymphomas. J Pathol 1997;183:432-439.

9 Felger RE, Macon WR, Kinney MC, et al. TIA-1 expression in lymphoid neoplasms. Identification of subsets with cytotoxic $\mathrm{T}$ lymphocyte or natural killer cell differentiation. Am J Pathol 1997;150: 1893-1900.

10 Yamashita Y, Yatabe Y, Tsuzuki T, et al. Perforin and granzyme expression in cytotoxic T-cell lymphomas. Mod Pathol 1998;11:313-323.

11 Yamashita Y, Nakamura S, Kagami Y, et al. Lennert's lymphoma. A variant of cytotoxic T-cell lymphoma? Am J Surg Pathol 2000;24:1627-1633.

12 Mori N, Yatabe Y, Oka K, et al. Expression of perforin in nasal lymphoma. Additional evidence of its natural killer cell derivation. Am J Pathol 1996;149:699-705.

13 Chan JK, Sin VC, Wong KF, et al. Nonnasal lymphoma expressing the natural killer cell marker CD56: a clinicopathologic study of 49 cases of an uncommon aggressive neoplasm. Blood 1997;86:4501-4513.

14 Mori N, Yamashita Y, Tsuzuki T, et al. Lymphomatous features of aggressive NK cell leukemia/lymphoma with massive necrosis, haemophagocytosis and EB virus infection. Histopathology 2000;37:363-371.

15 Cooke CB, Krenacs L, Stetler-Stevenson M, et al. Hepatosplenic T-cell lymphoma: a distinct clinicopathologic entity of cytotoxic $\gamma \delta$ T-cell origin. Blood 1996;88:4265-4274.

$16 \mathrm{Wu}$ H, Wasik MA, Przybylski G, et al. Hepatosplenic gamma-delta T-cell lymphoma as a late-onset posttransplant lymphoproliferative disorder in renal transplant recipients. Am J Clin Pathol 2000;113:487-496.

17 Gaulard P, Bourquelot P, Kanavaros P, et al. Expression of the alpha/beta and gamma/delta T-cell receptors in 57 cases of peripheral T-cell lymphomas. Identification of a subset of $\gamma / \delta$ T-cell lymphomas. Am J Pathol 1990;137:617-628.

18 Gonzalez CL, Medeiros LJ, Braziel RM, et al. T-cell lymphoma involving subcutaneous tissue. A clinicopathologic entity commonly associated with hemophagocytic syndrome. Am J Surg Pathol 1991;15: 17-27.

19 Salhany KE, Macon WR, Choi JK, et al. Subcutaneous panniculitis-like T-cell lymphoma: clinicopathologic, immunophenotypic, and genotypic analysis of alpha/ beta and gamma/delta subtypes. Am J Surg Pathol 1998;22:881-893.

20 Chott A, Haedicke W, Mosberger L, et al. Most CD56+ intestinal lymphomas are CD8+CD5- T-cell lymphomas of monomorphic small to medium size histology. Am J Pathol 1998;153:1483-1490.

21 Krenacs L, Wellmann A, Sorbara L, et al. Cytotoxic cell antigen expression in anaplastic large cell lymphomas of T- and null-cell type and Hodgkin's disease: evidence for distinct cellular origin. Blood 1997;89: 980-989.

22 McLean IW, Nakane PK. Periodate-lysine-paraformaldehyde fixative: a new fixative for immunoelectron microscopy. J Histochem Cytochem 1974;22: 1077-1083.

23 Tsunoda R, Terashima K, Takahashi K, et al. An ultrastructural study with enzyme-labeled antibody technique on immunoglobulin containing cells in human tonsils, especially in germinal centers. Acta Pathol Jpn 1978;28:53-75.

24 Hsu SM, Raine L, Fanger H. Use of avidin-biotinperoxidase complex (ABC) in immunoperoxidase techniques: a comparison between $\mathrm{ABC}$ and unlabeled antibody(PAP) procedures. J Histochem Cytochem 1981;29:577-580.

25 Bouroncle BA, Wiseman BK, Doan CA. Leukemic reticuloendotheliosis. Blood 1958;13:609-630.

26 Yam LT, Li CY, Lam KW. Tartrate-resistant acid phosphatase isoenzyme in the reticulum cells of leukemic reticuloendotheliosis. N Engl J Med 1971; 284:357-360.

27 Jaffe ES, Shevach EM, Frank MM, et al. Leukemic reticuloendotheliosis: Presence of a receptor for cytophilic antibody. Am J Med 1974;57:108-114.

28 Katayama I, Finkel HE. Leukemic reticuloendotheliosis. A clinicopathologic study with review of the literature. Am J Med 1974;157:115-126.

29 Naeim F, Smith GS. Leukemic reticuloendotheliosis. Cancer 1974;34:1813-1821.

30 King GW, Hurtubise PE, Sagone AL, et al. Leukemic reticuloendotheliosis. A study of the origin of the malignant cell. Am J Med 1975;59:411-416.

31 Katayama I, Yang JPS. Reassesment of a cytochemical test for differential diagnosis of leukemic reticuloendotheliosis. Am J Clin Pathol 1977;68:268-272.

32 Golomb HM, Vardiman JW. Response to splenectomy in 65 patients with hairy cell leukemia: an evaluation of spleen weight and bone marrow involvement. Blood 1983;61:349-352.

33 Schrek R, Donnelly WJ. Hairy cells in blood in lymphoreticular neoplastic disease and flagellated cells of normal lymph nodes. Blood 1966;27:199-211.

34 Bitter MA. Hairy cell leukemia and related disorders. In: Knowles DM (ed). Neoplastic Hematopathology, 2nd edn. Lippincott Williams \& Wilkins: Baltimore, 2001, pp 1531-1555.

35 Foucar K, Catovsky D. Hairy cell leukemia. In: Jaffe ES, Harris NL, Stein H, Vardiman JM (eds). World Health Organization Classification of Tumors. Tumors of Haematopoietic and Lymphoid Tissues. IARC Press, Lyon, 2001, pp 138-141.

36 Nanba K, Soban EJ, Bowling MC, et al. Splenic pseudosinuses and hepatic angiomatous lesions. Distinctive features of hairy cell leukemia. Am J Clin Pathol 1977;67:415-426.

37 Machii T, Tokumine Y, Inoue R, et al. Predominance of a distinct subtype of hairy cell leukemia in Japan. Leukemia 1993;7:181-186.

38 Shibayama H, Machii T, Yamaguchi M, et al. Early age onset of hairy cell leukemia presenting with leukocytosis. Int J Hematol 1996;64:287-290. 
39 Yamaguchi M, Machii T, Shibayama H, et al. Immunophenotypic features and configuration of immunoglobulin genes in hairy cell leukemia-Japanese variant. Leukemia 1996;10:1390-1394.

40 Sainati L, Matutes E, Mulligan S, et al. A variant of hairy cell leukemia resistant to $\alpha$-interferon. Clinical and phenotypic characteristics of 17 patients. Blood 1990;76:157-162.

41 Vardiman JW, Gilewski TA, Ratain MJ, et al. Evaluation of LeuM5(CD11c) in hairy cell leukemia by the alkaline phosphatase anti-alkaline phosphatase technique. Am J Clin Pathol 1988;90:250-256.

42 Schwarting R, Stein H, Wang CY. The monoclonal antibodies $\alpha$ S-HCL1( $\alpha$ Leu14) and $\alpha$ S-HCL3( $\alpha$ LeuM5) allow the diagnosis of hairy cell leukemia. Blood 1985;65:974-983.

43 Hsu S-M, Yang K, Jaffe ES. Hairy cell leukemia: a B cell neoplasm with a unique antigenic phenotype. Am J Clin Pathol 1983;80:421-428.
44 Foucar K. Chronic lymphoid leukemias and lymphoproliferative disorders. Mod Pathol 1999;12: 141-150.

45 Gruber G, Schwarzmeier JD, Shehata M, et al. Basic fibroblast growth factor is expressed by CD19/CD11cpositive cells in hairy cell leukemia. Blood 1999; 94:1077-1085.

46 Aziz KA, Till KJ, Chen H, et al. The role of autocrine FGF-2 in the distinctive bone marrow fibrosis of hairy cell leukemia (HCL). Blood 2003;102:1051-1056.

47 Janckila AJ, Gentile PS, Yam LT. Hemopoietic inhibition in hairy cell leukemia. Am J Hematol 1991;38: 30-39.

48 Khalaf W, Maina C, Byers J, et al. Interferon-alpha 2b and vesnarinone influence levels of tumor necrosis factor-alpha, apoptosis, or interleukin 6 in ESKOL, a hairy cell leukemic cell line. A potential cytokine and oncogene relationship regulating apoptosis is suggested. Leuk Res 2002;26:169-177. 